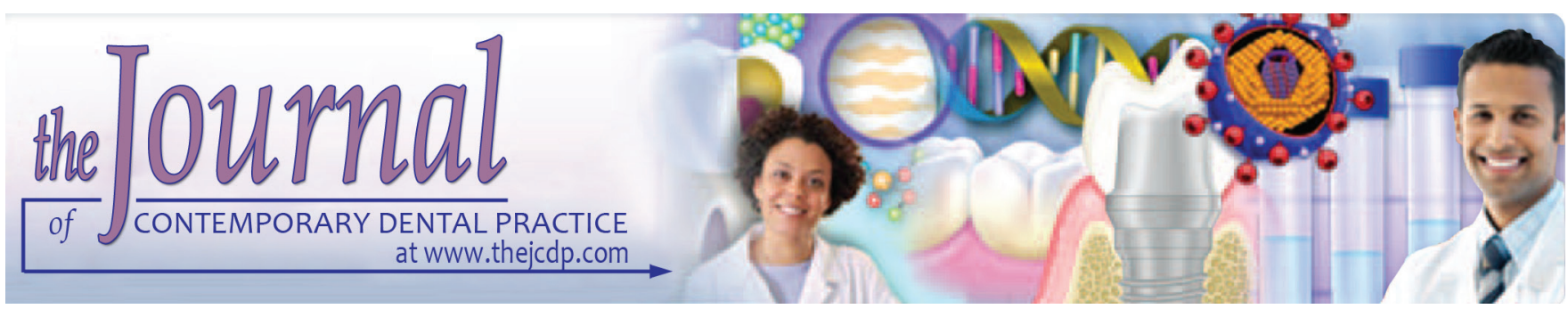

\title{
Evaluation of Tumor-associated Tissue Eosinophilia in Different Stages of Oral Squamous Cell Carcinoma using Special Stains: An in vitro Histopathological Study
}

${ }^{1} \mathrm{~S}$ Ladke Vaibhav, ${ }^{2} \mathrm{P}$ Lunawat Priya, ${ }^{3} \mathrm{C}$ Kapse Sonam, ${ }^{4} \mathrm{Koshti}$ Supriya, ${ }^{5}$ Yadav Garima, ${ }^{6}$ Shaikh Sabeer

${ }^{7}$ Parag Juvale, ${ }^{8}$ Gitanjali Javir

\begin{abstract}
Aim: To evaluate the tissue eosinophilia in different stages and grades of oral squamous cell carcinoma (OSCC) and correlate its possible role as a prognosticator in primary OSCC using special stains like Congo red and carbol chromotrope.

Materials and methods: Forty-five intraoral histopathologically proven cases of OSCC were selected (15 cases each of well-differentiated squamous cell carcinoma (WDSCC), moderately differentiated squamous cell carcinoma (MDSCC), and poorly differentiated squamous cell carcinoma (PDSCC)). Three sections of $4 \mu \mathrm{m}$ were taken for each case. All slides were stained using routine stain, i.e., hematoxylin and eosin (H\&E), and special stains, i.e., carbol chromotrope and Congo red respectively, for studying tissue eosinophils in all these groups. Histopathological evaluation was performed on paraffin sections for calculating the quantitative eosinophil distribution by two separate observers who were blinded to clinical and histopathological data. Tumor-associated tissue eosinophilia (TATE) was calculated using the density method.
\end{abstract}

Results: An increase in the degree of TATE from stage I to stage IV suggested that elevated tissue eosinophilia was seen with an increasing size of primary tumor. Also an increase in TATE was observed with an increasing grade of OSCC. Chromotrope

\footnotetext{
${ }^{1-6}$ Department of Oral Pathology and Microbiology, M.A. Rangoonwala College of Dental Science \& Research Centre Pune, Maharashtra, India; Maharashtra University of Health Sciences, Nashik, Maharashtra, India

${ }^{7}$ Department of Chemistry, Georgia State University, Atlanta Georgia, USA

${ }^{8}$ Department of Biotechnology, Sinhgad College of Engineering Pune, Maharashtra, India

Corresponding Author: S Ladke Vaibhav, Department of Oral Pathology and Microbiology, M.A. Rangoonwala College of Dental Science \& Research Centre, Pune, Maharashtra, India Maharashtra University of Health Sciences, Nashik, Maharashtra India, Phone: +919923132047, e-mail: drvaibhavladke@gmail. com
}

stain was found to be a much better and more specific stain for eosinophils, and gave more accurate eosinophil count compared with H\&E and Congo red.

Conclusion: The findings of the present study highlight the significance of eosinophil counting and that it can be used as an additional morphological parameter in the grading of OSCC which can also be included in the biopsy report.

Keywords: Eosinophilia, Oral squamous cell carcinoma, Prognosis, Stains, Tumor stroma, Tumor-associated tissue eosinophilia.

How to cite this article: Vaibhav SL, Priya PL, Sonam CK, Supriya K, Garima Y, Sabeer S, Juvale P, Javir G. Evaluation of Tumor-associated Tissue Eosinophilia in Different Stages of Oral Squamous Cell Carcinoma using Special Stains: An in vitro Histopathological Study. J Contemp Dent Pract 2018;19(5):579-586.

\section{Source of support: Nil}

Conflict of interest: None

\section{INTRODUCTION}

Oral squamous cell carcinoma, although extensively studied and researched, still remains one of the largest causes of adult mortality. It is the sixth most common cancer globally when grouped together with pharyngeal cancers. ${ }^{1}$ Poorer prognosis and survival rates in developing countries are largely due to the late stage of disease at first presentation of patient and lack of adequate follow-up. Early predictors of cancer recurrence at time of diagnosis are a valuable missing link in OSCC. A recent emerging area of interest is the tumor stromal response, the influence of tumor microenvironment, and inflammation in the behavior of various cancers.

It is suggested that the relationship between cancer and inflammation occurs through two pathways: an extrinsic pathway which is driven by inflammatory 
signals and an intrinsic pathway driven by genetic alterations that cause both inflammation and neoplasia. ${ }^{2}$ Lymphocytes and natural killer cells have been studied in detail as an inflammatory component and their role in OSCC. But little is known about other inflammatory cells like eosinophils and their role in cancer.

Wharton Jones first described eosinophils as "coarse granular cells" and later Paul Ehrlich described it as "eosinophils." ${ }^{3}$ They are characterized by the presence of abundant cytoplasm with coarse reflective granules ${ }^{4}$ and are notable by their tinctorial properties showing bright red staining with acid aniline dyes. They are involved in initiation and propagation of diverse inflammatory responses as well as modulators of innate and adaptive immunity. ${ }^{5}$ Extensive tissue eosinophilia has been studied in many cancers including OSCC. ${ }^{6}$ Tumor-associated tissue eosinophilia is defined as "eosinophilic stromal infiltration of a tumor not associated with tumor necrosis or ulceration." This was first described by Przewoski ${ }^{7}$ in 1896 in carcinoma of cervix. The TATE is characterized by the presence of eosinophils as a constituent of peritumoral and intratumoral inflammatory infiltrate. ${ }^{8,9}$ Eosinophils are hypothesized to have direct tumoricidal activity with release of cytotoxic proteins and also act indirectly by enhancing the permeability into tumor cells, facilitating penetration of tumor-killing cytokines. Additionally, the eosinophils may have tumor angiogenesis effect by producing several angiogenic factors.

Six correlations of tissue eosinophilia with prognosis have shown variable results in OSCC that has been related to a favorable $\mathrm{e}^{8,10}$ and to an unfavorable ${ }^{11,12}$ prognosis or even having no influence on patient outcome. ${ }^{7,13}$ Few studies have compared eosinophil counts between in situ neoplastic lesions and invasive neoplastic lesions and found higher counts in neoplastic lesions, suggesting that elevated eosinophil count is a histopathological marker showing stromal invasion. Most of the times, intact eosinophils can be identified in tissue sections stained with H\&E staining, but sometimes they exhibit an uncommon morphology, making their recognition difficult. In such situations, a special technique like autofluorescence or immunohistochemistry may be needed to detect the presence of intact or degranulating eosinophils, particularly in tumors. ${ }^{14,15}$ Special stains like Congo red and carbol chromotrope have also proved to be a valuable diagnostic tool for the detection of eosinophils because of their unique property to bind with eosinophils. ${ }^{16,17}$ In view of this, the present study was designed to evaluate tissue eosinophilia in different stages and grades of OSCC and correlating its possible role as a prognosticator in primary OSCC, using special stains like Congo red and carbol chromotrope.

\section{MATERIALS AND METHODS}

Forty-five intraoral histopathologically proven cases of OSCC were selected (15 cases each of WDSCC, MDSCC, and PDSCC). The grading was decided when the agreement of at least three observers on the same grade was done. Broders' system was followed for the grading of OSCC. Subjects with marked intraoral soft tissue pathology, with extensive ulceration and/or necrosis, or having been treated with chemotherapy or radiotherapy before surgery, medically compromised patients or with any other systemic debilitating disorder were excluded from the study. These 45 cases were grouped as follows: group I-15 clinically diagnosed cases of WDSCC. Group II-15 clinically diagnosed cases of MDSCC. Group III-15 clinically diagnosed cases of PDSCC. Group IV-15 clinically normal cases as the control group included normal tissue obtained from buccal mucosa of healthy individuals undergoing third molar extraction, gingivectomy, alveoloplasty, as well as archival blocks diagnosed as normal. All the cases were numbered serially and numbering was done randomly. Three sections of $4 \mu \mathrm{m}$ were taken for each case. All slides were stained using routine stain, i.e., $\mathrm{H} \& \mathrm{E}$, and special stains, i.e., carbol chromotrope ${ }^{18}$ and Congo red, ${ }^{19,20}$ respectively, for studying tissue eosinophils in all these groups.

A histopathological evaluation was performed on paraffin sections of representative portions of the tumors for identifying eosinophil distribution and quantitative eosinophil distribution of tumor sections was performed by two separate observers who were blinded to clinical and histopathological data. The TATE was calculated by using the density method proposed by Alkhabuli and High, ${ }^{21}$ as this method may have more relationship with function when compared with classical method. The highest eosinophil density surface area was then selected using a grid of $0.3 \mathrm{~mm}$ side (Fig. 1) and was counted for each case in H\&E stain, carbol chromotrope, Congo

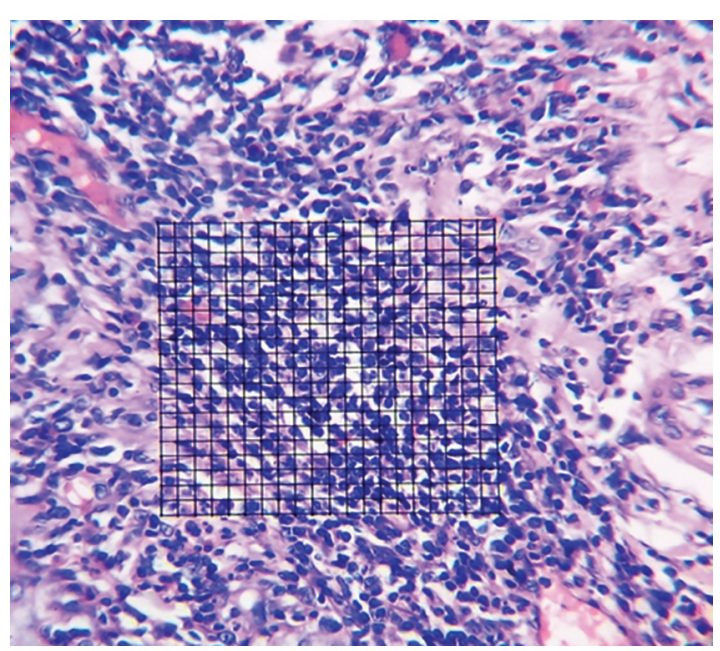

Fig. 1: High-density area of eosinophils selected randomly with grid eyepiece (magnification 400x) 


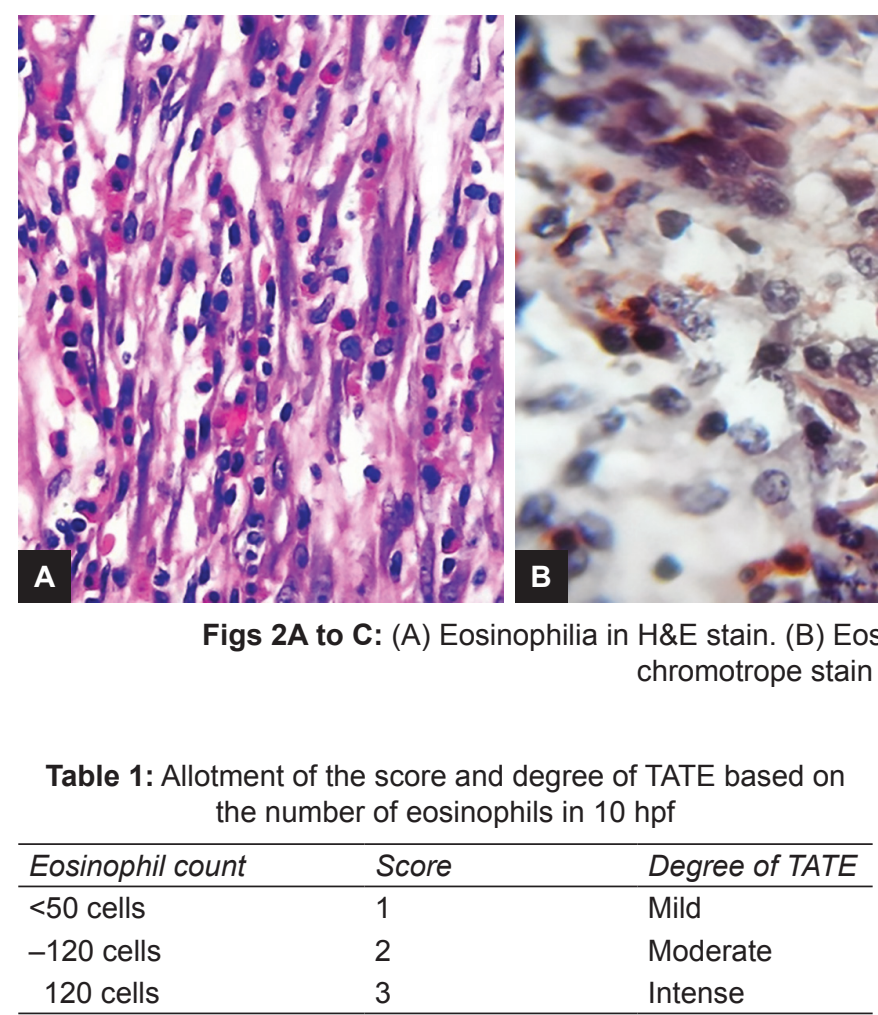

red-stained sections under 40× magnifications (Fig. 2). They were counted in 10 consecutive high-power fields (hpf) and recorded as eosinophils $/ 10 \mathrm{hpf}$. Following the literature reviewed, only nucleated cells with intensely red cytoplasmic granules were accepted as eosinophils. Care was taken to exclude red blood cells with superimposed mononuclear and polymorphonuclear cells and also those confined to lymphovascular space. ${ }^{13}$ Eosinophilia associated with tumor necrosis or ulceration were excluded. ${ }^{8}$ Average eosinophil count of all the three stains and of the two observers was taken for evaluation. We evaluated TATE only quantitatively based on the count as mild, moderate, or intense (Table 1).

\section{Statistical Analysis}

The statistical significance of intergroup difference of mean of quantitative characteristics was tested using one-way analysis of variance (ANOVA) with Bonferroni's post hoc test for multiple group comparisons.

The statistical significance of intergroup difference of mean of qualitative variables was tested using chisquare test.

\section{OBSERVATION AND RESULTS}

The study included a total of 45 cases of OSCC, of which 34 cases were males $(75.6 \%)$ and 11 cases were females (24.4\%). The age of the patients ranged from 35 to 78 years (mean 53.6 years; standard deviation 10.6) with majority of the cases above the age of 50 years $(n=27 ; 60 \%$ ).
The most common site of involvement was the alveolus $(\mathrm{n}=20 ; 44.4 \%)$, followed by the buccal mucosa $(\mathrm{n}=14$; $31.1 \%)$, tongue $(n=04 ; 8.9 \%)$, gingiva $(n=03 ; 6.7 \%)$, lips ( $n=01 ; 2.2 \%)$, maxilla $(n=2 ; 4.4 \%)$, and floor of the mouth $(\mathrm{n}=1 ; 2.2 \%)(\mathrm{Graph} 1)$. All the OSCC cases were clinically categorized based on clinical Tumor, Node, Metastasis (TNM) staging in which stage $\mathrm{I}=08$, stage $\mathrm{II}=14$, stage III $=16$, and stage IV $=07$ (Graph 2). Based on histopathologic grading, 15 cases each were included of WDSCC, MDSCC, and PDSCC. The TATE was evaluated and calculated in each stain, clinical stage, and histopathological grade. The pair-wise assessment of eosinophil count was done by two observers in all three stains. In all the three stains, carbol chromotrope stain was found to be much better and more specific stain for eosinophils, and which gave a more accurate eosinophil count (Graph 3). All the staining techniques showed increased eosinophil count from stage I to stage IV and it was significantly higher in stage IV compared with stages I and III ( $\mathrm{p}$-value $<0.05$ for all, except for H\&E technique for stage I vs stage IV) (Tables 2 and 3). The distribution of degree of TATE differs

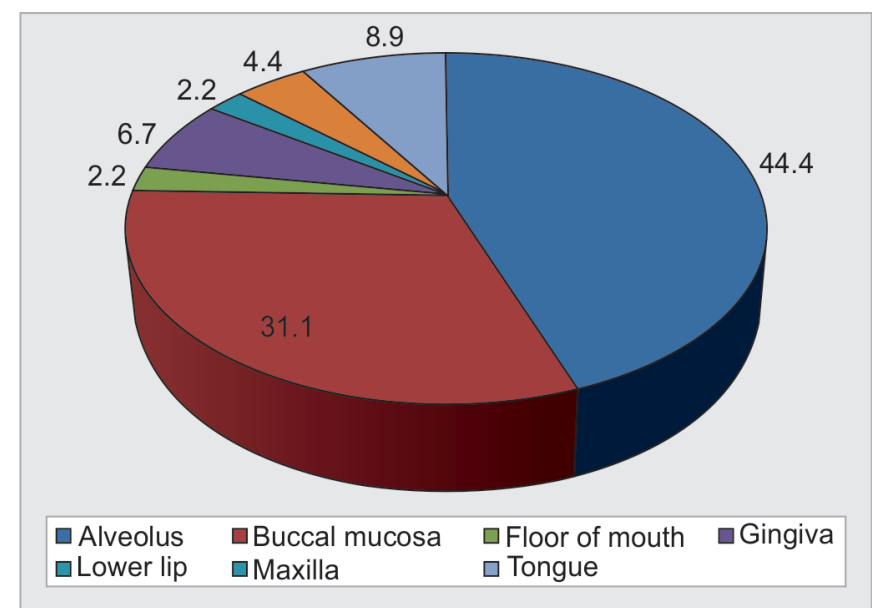

Graph 1: Distribution of patients according to the site of primary tumor $(n=45)$ 


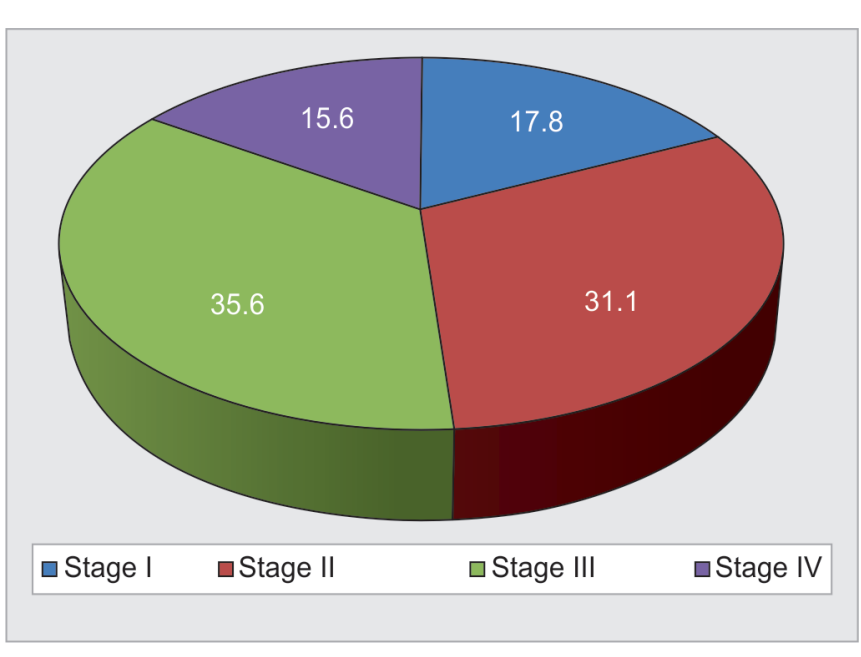

Graph 2: The distribution of patients according to clinical TNM staging $(n=45)$

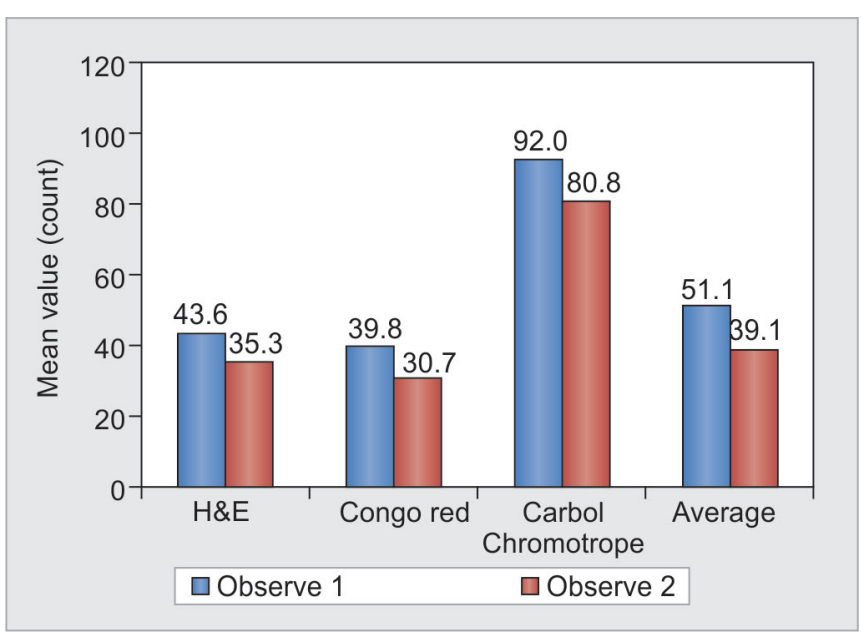

Graph 3: The pair-wise assessment of eosinophil count by two observers in three stains $(n=45)$

Table 2: The distribution of eosinophil count according to clinical staging $(n=45)$

\begin{tabular}{lllll}
\hline Eosinophil count & Stage I $(n=8)$ & Stage II $(n=14)$ & Stage III $(n=16)$ & Stage IV $(n=7)$ \\
\hline H\&E & $29.5 \pm 12.1$ & $41.1 \pm 14.3$ & $28.3 \pm 11.4$ & $100.1 \pm 30.9$ \\
Congo red & $21.5 \pm 12.8$ & $52.4 \pm 18.7$ & $42.1 \pm 10.6$ & $123.7 \pm 34.1$ \\
Carbol chromotrope & $20.9 \pm 7.2$ & $83.6 \pm 31.1$ & $78.9 \pm 27.7$ & $220.1 \pm 62.9$ \\
Average & $24.4 \pm 10.5$ & $59.5 \pm 21.1$ & $50.1 \pm 14.7$ & $147.3 \pm 40.7$ \\
\hline
\end{tabular}

Values are mean \pm standard error of mean

Table 3: The statistical comparison of eosinophil count according to clinical staging $(n=45)$

\begin{tabular}{llll}
\hline \multirow{2}{*}{ Eosinophil count } & \multicolumn{2}{c}{$p$-value (interstaging comparisons) } \\
\cline { 2 - 4 } H\&E & Stage I vs II & Stage I vs III & Stage I vs IV \\
Congo red & $0.999^{\mathrm{NS}}$ & $0.999^{\mathrm{NS}}$ & $0.086^{\mathrm{NS}}$ \\
Carbol chromotrope & $0.999^{\mathrm{NS}}$ & $0.999^{\mathrm{NS}}$ & $0.013^{*}$ \\
Average & $0.999^{\mathrm{NS}}$ & $0.999^{\mathrm{NS}}$ & $0.009^{* *}$ \\
Eosinophil count & $0.999^{\mathrm{NS}}$ & $0.999^{\mathrm{NS}}$ & $0.011^{*}$ \\
H\&E & Stage II vs III & Stage II vs IV & Stage III vs IV \\
Congo red & $0.999^{\mathrm{NS}}$ & $0.129^{\mathrm{NS}}$ & $0.030^{*}$ \\
Carbol chromotrope & $0.999^{\mathrm{NS}}$ & $0.086^{\mathrm{NS}}$ & $0.028^{*}$ \\
Average & $0.999^{\mathrm{NS}}$ & $0.078^{\mathrm{NS}}$ & $0.050^{*}$ \\
\hline
\end{tabular}

p-values by ANOVA with Bonferroni's post hoc test for multiple group comparisons. $p$-value $<0.05$ is considered statistically significant. ${ }^{*} p$-value $<0.05,{ }^{* *} p$-value $<0.01$, NS: Statistically nonsignificant

significantly between all stages (Table 4). This increase degree of TATE from stage I to stage IV suggested that elevated tissue eosinophilia was seen with increasing size of primary tumor. The distribution of degree of TATE in all grades of OSCC statistically did not differ significantly

Table 4: The statistical comparison of degree of TATE according to clinical staging $(n=45)$

\begin{tabular}{llll}
\hline \multirow{2}{*}{ Degree of TATE } & \multicolumn{3}{c}{$p$-value (interstaging comparisons) } \\
\cline { 2 - 4 } & Stage I vs II & Stage I vs III & Stage I vs IV \\
\hline 0.617 NS & 0.417 NS & $0.002^{* *}$ \\
Stage II vs III & Stage II vs IV & Stage III vs IV \\
0.571 NS & $0.003^{* *}$ & $0.009^{* *}$ \\
\hline
\end{tabular}

p-values by chi-square test. $p$-value $<0.05$ is considered to be statistically significant. ${ }^{* *} p$-value $<0.01$, NS: Statistically nonsignificant but there was an increase in intense eosinophilia in PDSCC compared with MDSCC and WDSCC (Table 5 and Graph 4). These observations suggested increased TATE with increasing grade of OSCC (Graph 5). Around 30 cases showed focally and mildly distributed eosinophilia, whereas five cases showed a diffuse distribution of eosinophils. Eosinophils were noticed mainly in invasive tumor front (ITF) stroma and near vascular areas (Fig. 3). They were absent or seen in very less amount in the area of densely diffuse infiltrate of chronic inflammatory cells, mainly lymphocytes and plasma cells (Fig. 4).

\section{DISCUSSION}

Oral cancer is an important global health concern accounting for an estimated 275,000 cases and 128,000 
Table 5: The distribution of eosinophil count according to pathological grading $(n=45)$

\begin{tabular}{lllllll}
\hline & & & \multicolumn{3}{c}{$p$-value (intergroup comparisons) } \\
\cline { 3 - 7 } & & & WDSCC vs & WDSCC vs & MDSCC vS \\
Eosinophil count & WDSCC $(n=15)$ & MDSCC $(n=15)$ & PDSCC $(n=15)$ & MDSCC & $P D S C C$ & $P D S C C$ \\
\hline H\&E & $27.4 \pm 11.7$ & $33.7 \pm 9.5$ & $69.9 \pm 19.7$ & $0.999 \mathrm{NS}$ & $0.126 \mathrm{NS}$ & $0.242 \mathrm{NS}$ \\
Congo red & $30.8 \pm 10.3$ & $41.5 \pm 9.7$ & $90.7 \pm 23.9$ & $0.999 \mathrm{NS}$ & $0.035^{*}$ & $0.109 \mathrm{NS}$ \\
Carbol chromotrope & $33.3 \pm 10.7$ & $60.8 \pm 17.2$ & $181.9 \pm 44.4$ & $0.999 \mathrm{NS}$ & $0.002^{* *}$ & $0.012^{*}$ \\
Average & $30.7 \pm 10.7$ & $45.7 \pm 11.4$ & $114.4 \pm 27.8$ & $0.999 \mathrm{NS}$ & $0.008^{* *}$ & $0.035^{*}$
\end{tabular}

Values are mean \pm standard error of mean. p-values by ANOVA with Bonferroni's post hoc test for multiple group comparisons. $p$-value $<0.05$ is considered to be statistically significant. ${ }^{*} p$-value $<0.05,{ }^{* *} p$-value $<0.01$, NS: Statistically nonsignificant

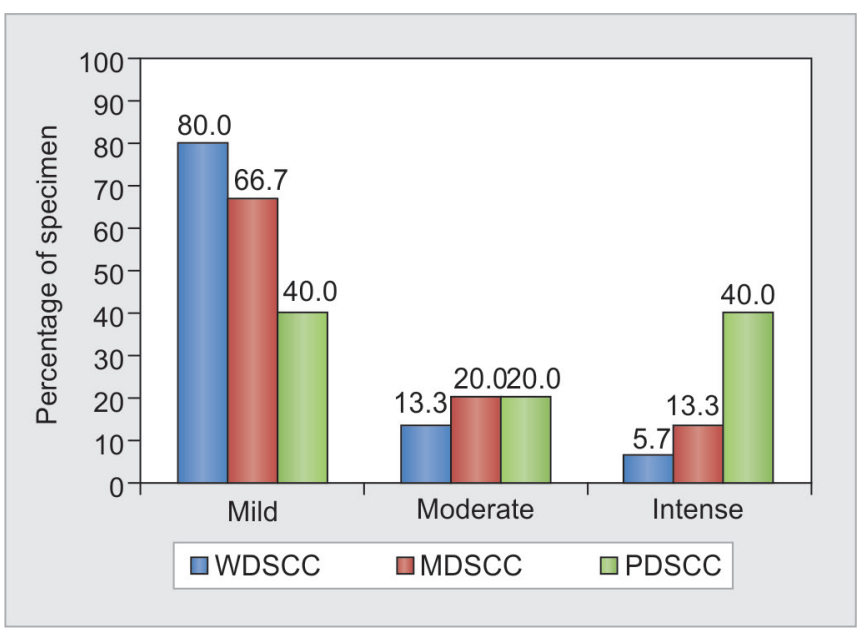

Graph 4: The pair-wise assessment of degree of TATE by two observers $(n=45)$

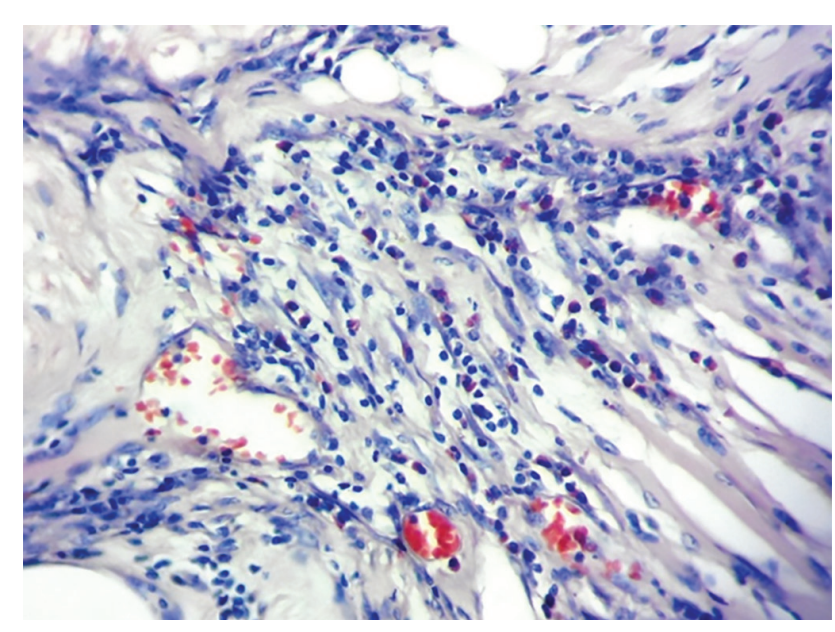

Fig. 3: Focally and densely spread eosinophils near invasive tumor front and vascular areas

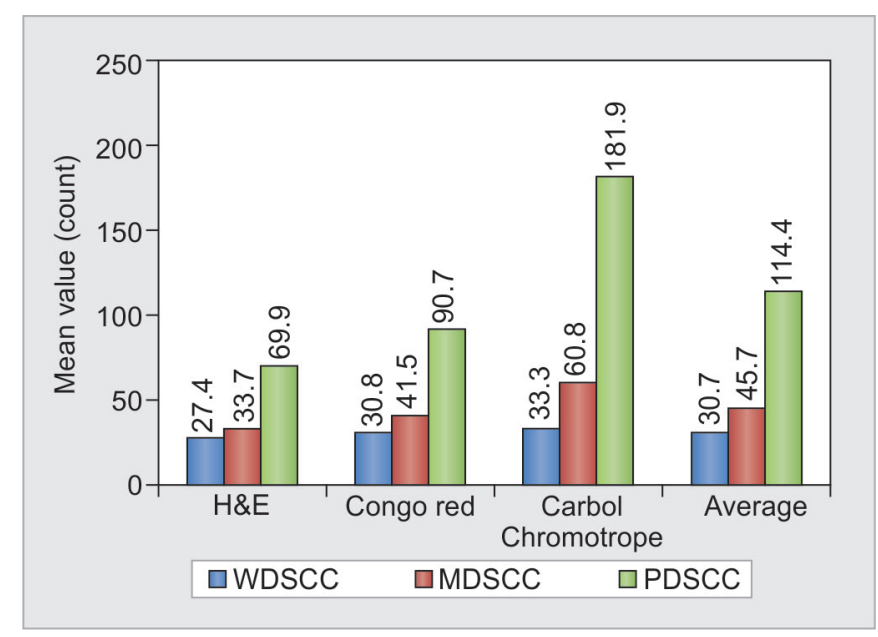

Graph 5: The distribution of eosinophil count according to clinical staging $(n=45)$

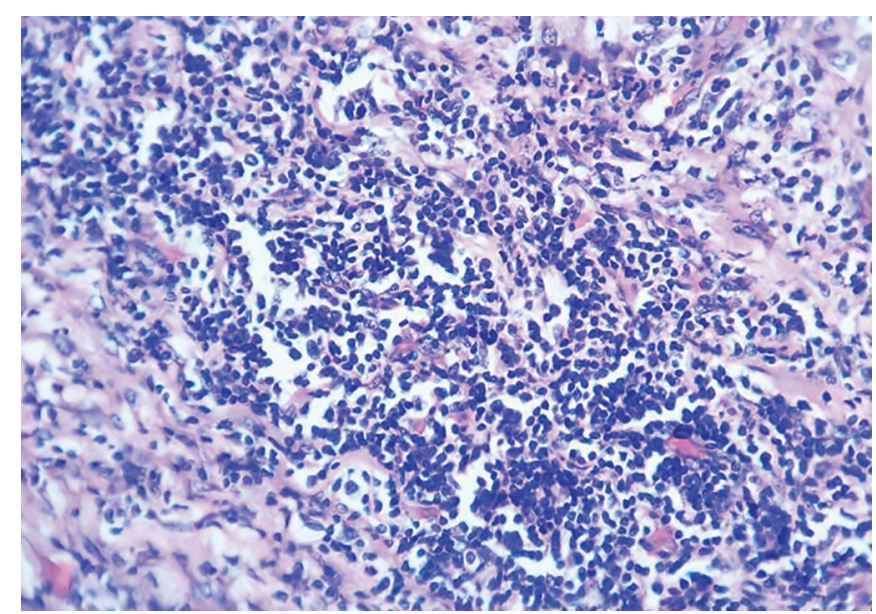

Fig. 4: Eosinophils are absent or seen in very less amount in the area of densely diffuse infiltrate of chronic inflammatory cells, mainly lymphocytes and plasma cells

are considered as important indicators of biological behavior of tumor tissue. ${ }^{23}$ Tumor infiltration by stromal cells has been a curious topic for over a century for the researchers. ${ }^{24}$ However, most of the pathology reports rarely include the presence, type, or amount of stromal inflammatory infiltrate in the tumor tissue. ${ }^{25}$ This continues despite the fact that a better prognosis is often associated with the presence of a stromal inflammatory response. ${ }^{24,25}$ The ITF in tumor tissue is considered as death annually. ${ }^{22}$ This motivates the search for factors with prognostic relevance in order to better understand the nature of OSCC and the individual management of OSCC patients. ${ }^{17}$ The underlying tumor stroma and its interaction with tumor cells have been considered as an important area in cancer research. The stroma shows various important features like increased angiogenesis, presence of varying degree of inflammatory infiltrate, desmoplastic stromal reaction and invasion, which 
an important hyperactive area with active and complex interaction between tumor cells and stromal tissue. The ITF contains mainly aggressive cells which exhibit significant molecular events that play an important role in tumor spread and also show less differentiation of tumor tissue than the remaining parts of the tumor. ${ }^{26}$ The ITF has gained a lot of attention in the past decade as an important prognosticator of human malignancies. ${ }^{27}$ It is thus worthwhile to investigate the stromal eosinophils and their role at the tumor edge. The present study aimed to evaluate TATE in different clinical stages of OSCC, along with the different histopathological grades using special stains which may help in understanding the dual function of the eosinophils in OSCC.

The present study included 45 cases of OSCC, out of which $75.6 \%$ were males and $24.4 \%$ were females. Numerous studies have highlighted that females have a much lower annual incidence rate than males and show a male-to-female gender ratio of $3: 1 .^{28}$ In our study, the ratio was 3.09:1, which suggested a male preponderance. The male predominance in our study may be due to the predominant habits of tobacco chewing and smoking habit in males, as $75 \%$ of the cases were having tobacco habit. The majority of study cases were above the age group of 50 years. This finding reinforces the concept that oral cancer is a disease of increasing age as approximately $95 \%$ of oral cancer occurs in patients older than 40 years as described by Lynch et al. ${ }^{29}$ In the present study also, approximately $93.3 \%$ patients were older than 40 years. As the high-density method is more precise for TATE evaluation, this method was selected in the present study. Lorena et $\mathrm{al}^{15}$ have reported the $H \& E$ technique to be as reliable as the immunostaining technique for the identification of eosinophils.

In the present study, we used two special stains like Congo red and carbol chromotrope stain along with routine H\&E stain that could better demonstrate TATE. The TATE was demonstrated more effectively by Congo red staining as compared with H\&E staining. Carbol chromotrope showed tissue eosinophils more prominently and distinctly as compared with Congo red and H\&E stains. Furthermore, the carbol chromotrope staining method is simple, cost-effective, and a superior staining method for eosinophils and can be considered for routine histopathology of OSCC. Joshi and Kaijkar, ${ }^{30}$ in their study, had compared H\&E and Congo red staining and concluded that Congo red staining has a higher sensitivity in staining eosinophils over routine $\mathrm{H} \& \mathrm{E}$, which was in accordance with our study. Debta et $\mathrm{al}^{16}$ compared Congo red and carbol chromotrope and confirmed that carbol chromotrope stain was better than Congo red, as was seen in our study.

In the head and neck SCC, it has been reported that the presence of tissue eosinophils ranges between 22 and
$89 \% .{ }^{31}$ In the present study, we observed that TATE was present in $88 \%$ (40 out of 45 ) cases, which is in accordance with other studies. In the present study, eosinophils were found in most cases of OSCC. There was elevated TATE in stages III and IV, so increased eosinophilia was associated with T3 and T4, suggestive of increased eosinophil count with increased primary tumor size. Celestina Dawn Peter et $\mathrm{al}^{32}$ have also reported an increase in eosinophil count with an increase in the tumor size. Oliveira et $\mathrm{al}^{9}$ showed absent/mild eosinophils in early clinical stages, i.e., stages I and stage II while significantly higher eosinophilia was seen in stages III and IV, suggesting increased eosinophilia with increasing clinical stages. These results are in accordance with our study. Nedakargahi et al, ${ }^{33}$ in their study, found an increased eosinophil count from normal to dysplastic mucosa and OSCC. Also, increased eosinophilia was noted from mild to severe in different levels of dysplastic mucosa and from WDSCC to PDSCC.

In the present study also, eosinophilia increased from mild to intense with increasing grades of the OSCC cases and they were found intimately associated with ITF stroma and vascular components. ${ }^{30}$ Although the findings of our study suggested an increase in the eosinophil count with an increasing grade of OSCC, it is still not established whether their presence is a primary reaction which influences behavior of the tumor or they are just a coincidental or secondary phenomenon elicited by a more fundamental biologic process. More studies related to the activity of eosinophils and their enzymes within OSCC may help to elucidate their exact role as antitumor activity or tumor-promoting activity. According to Joshi and Kaijkar, ${ }^{30}$ no correlation was noted between the eosinophilic infiltration and the histologic grades of OSCC. However, this may be because the distribution of OSCC cases according to histologic grades was unequal and not consistent.

A conceivable explanation for the disparity in the results of various studies could be due to the lack of a standard criteria for grading TATE that is universally followed, ${ }^{8}$ and also use of biopsy specimens that run the risk of being unrepresentative.

In our study, we noted a slight variation in the degree of TATE evaluated by two observers which, however, was not statistically significant (Kappa statistic $=0.160$, p-value $=0.253$ ), which highlights the need for more objective and standardized criteria for eosinophil counting. Conflicting reports regarding the role of tissue eosinophil in the tumor stroma have been reported. Numerous studies $^{8,17}$ support that an increased number of tissue eosinophil is associated with the antitumoral role and shows good prognosis. But the studies done by Wong

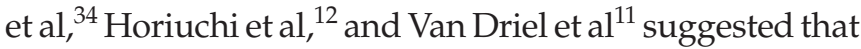
tissue eosinophils play a tumor-promoting role in OSCC. 
Oliveria et $\mathrm{al}^{9}$ found that TATE showed no prognostic value in OSCC and suggested that intense TATE seems to reflect the stromal invasion of the OSCCs that occur in advanced clinical stage. ${ }^{35}$ Looi $^{36}$ has shown no influence on the prognosis. These conflicting reports warrant a well-planned study which focuses on the activity of eosinophils within tumor stroma and whether tumor microenvironment influences the activity of eosinophils followed by a long-term follow-up of patients to verify the correlation between eosinophilia and prognosis. Our results support the evidence that eosinophilic tumor infiltration may play a important role to define prognosis in oral cancer which is also suggested by Goldsmith et al. ${ }^{37,38}$ Thus, a quantitative assessment of eosinophils can prove to be an important aspect of the microscopic evaluation of OSCC which is often neglected. ${ }^{17}$ In developing countries like India, OSCC is more prevalent among low socioeconomic status groups. Such patients are often lost to follow-up and do not comply with lifestyle modifications. Thus, early identification of recurrence at the time of diagnosis by including the evaluation of tissue eosinophilia as a routine histopathological parameter will be useful in identifying patients at risk and modifying treatment modalities. ${ }^{39}$

\section{CONCLUSION}

The findings of the present study highlight significance of eosinophil counting and that it can be used as an additional morphological parameter in the grading of OSCC, which can also be included in the biopsy report. Special stains, such as carbol chromotrope and Congo red are inexpensive and simplify the detection of eosinophils, enabling good and rapid results. They can thus be used as an adjunct to routine $\mathrm{H} \& \mathrm{E}$ in the evaluation of eosinophils in OSCC.

\section{AREAS FOR FUTURE RESEARCH}

The present study reports increased eosinophilia in increasing grades of OSCC; hence, further research should be aimed at evaluating the activity of tissue eosinophils and correlating it with prognosis by a long-term follow-up in OSCC. The biological signals responsible for such recruitment processes also remain to be identified and whether these signals also play a role in determining the activity of the eosinophils as antitumor or tumor promoting.

\section{REFERENCES}

1. Parkin DM, Bray F, Ferlay J, Pisani P. Global cancer statistics, 2002. CA Cancer J Clin 2005 Mar-Apr;55(2):74-108.

2. Bektaş-Kayhan K. Role of inflammation in oral squamous cell carcinoma. Available from: www.intechopen.com

3. Lowe D, Jorizzo J, Hutt MS. Tumour-associated eosinophilia: a review. J Clin Pathol 1981 Dec;34(12):1343-1348.
4. Saraswathi TR, Nalinkumar S, Ranganathan K, Umadevi R, Elizabeth J. Eosinophils in health and disease: an overview. J Oral Maxillofac Pathol 2003;7(2):31-33.

5. Hogan SP, Rosenberg HF, Moqbel R, Phipps S, Foster PS, Lacy P, Kay AB, Rothenberg ME. Eosinophils: biological properties and role in health and disease. Clin Exp Allergy 2008 May;38(5):709-750.

6. Pereira MC, Oliveira DT, Kowalski LP. The role of eosinophils and eosinophil cationic protein in oral cancer: a review. Arch Oral Biol 2011 Apr;56(4):353-358.

7. Przewoski E. Ueber die locale eosinophilie beim krebs nebst Bemerkungen iiber die Bedeutung der eosinopbilen zellen im Allgemeinen. Centralbl f Allg Path u Path Anat1896;5:177-191.

8. Dorta RG, Landman G, Kowalski LP, Lauris JRP, Latorre MRDO, Oliveira DT. Tumour-associated tissue eosinophilia as a prognostic factor in oral squamous cell carcinomas. Histopathology 2002 Aug;41(2):152-157.

9. Oliveira DT, Tjioe KC, Assao A, Sita Faustino SE, Lopes Carvalho A, Landman G, Kowalski LP. Tissue eosinophilia and its association with tumoral invasion of oral cancer. Int J Surg Pathol 2009 Jun;17(3):244-249.

10. Thompson AC, Bradley PJ, Griffin NR. Tumor associated tissue eosinophilia and long-term prognosis for carcinoma of the larynx. Am J Surg 1994 Nov;168(5):469-471.

11. Van Driel WJ, Hogendoorn PCW, Jansen FW, Zwinderman AH, Trimbos JB, Fleuren GJ. Tumor-associated eosinophilic infiltrate of cervical cancer is indicative for a less effective immune response. Hum Pathol 1996 Sep;27(9):904-911.

12. Horiuchi K, Mishima K, Ohsawa M, Sugimura M, Aozasa K. Prognostic factors for well-differentiated squamous cell carcinoma in the oral cavity with emphasis on immunohistochemical evaluation. J Surg Oncol 1993 Jun;53(2):92-96.

13. Tadbir AA, Ashraf MJ, Sardari Y. Prognostic significance of stromal eosinophilic infiltration in oral squamous cell carcinoma. J Craniofac Surg 2009 Mar;20(2):287-289.

14. Samoszuk M. Eosinophils and human cancer. Histol Histopathol 1997 Jul;12(3):807-812.

15. Lorena CM, Dorta RG, Landman G, Nonogaki S, Oliveira DT. Morphometric analysis of the tumor associated tissue eosinophilia in the oral squamous cell carcinoma using different staining techniques. Histol Histopathol 2003 Jul;18(3):709-713.

16. Debta P, Debta FM, Chaudhary M, Dani A. Evaluation of infiltration of immunological cells (tumour associated tissue eosinophils and mast cells) in oral squamous cell carcinoma by using special stains. Br J Med Med Res 2012 Jan-Mar;2(1):75-85.

17. Debta P, Debta FM, Chaudhary M, Wadhwan V. Evaluation of prognostic significance of immunological cells (tissue eosinophil and mast cell) infiltration in oral squamous cell carcinoma. J Cancer Sci Ther 2011;3(8):201-204.

18. Payne RW, Hill RH. A routine method for staining eosinophils in sputum. J Clin Pathol 1963 Jul;16(4):387.

19. Bancraft JD, Gamble M. Theory and practice of histological techniques. 4th ed. Churchill Livingstone; 2002. p. 346-347.

20. Culling CFA, Allison RT, Barr WT. Cellular pathology technique. 4th ed. Butterworth and Co; 1985. pp. 460-461.

21. Alkhabuli JO, High AS. Significance of eosinophil counting in tumor associated tissue eosinophilia (TATE). Oral Oncol 2006 Sep;42(8):849-850.

22. Neville BW, Damm DD, Allen CM, Chi A. Oral and maxillofacial pathology. 2nd ed. Philadelphia (PA): WB Saunders; 2002. pp. 356-366. 
23. Alrawi SJ, Tan D, Stoler DL, Dayton M, Anderson GR, Mojica P, Douglas W, Hicks W Jr, Rigual N, Loree T. Tissue eosinophilic infiltration: a useful marker for assessing stromal invasion, survival and locoregional recurrence in head and neck squamous neoplasia. Cancer J 2005 May-Jun;11(3):217-225.

24. Underwood JCE. Lymphoreticular infiltration in human tumours: prognostic and biological implications: a review. Br J Cancer 1974 Dec;30(6):538-548.

25. Loachim HL, Dorset BH, Paludi E. The immune response at the tumor site in lung carcinoma. Cancer (Phila) 1976 Dec;38(6):2296-2309.

26. Sharma M, Sah P, Sharma SS, Radhakrishnan R. Molecular changes in invasive front of oral cancer. J Oral Maxillofac Pathol 2013 May-Aug;17(2):240-247.

27. Rakesh N, Devi Y, Majumdar K, Reddy SS, Agarwal K. Tumour associated tissue eosinophilia as a predictor of locoregional recurrence in oral squamous cell carcinoma. J Clin Exp Dent 2015 Feb;7(1):e1-e6.

28. Neville BW, Damm DD, Allen CM, Bouquot JE. Oral and maxillofacial pathology. 2nd ed. Philadelphia (PA): Saunders; 2005. pp. 356-363.

29. Lynch MA, Brightman VJ, Greenberg MS. Burkit's oral medicine diagnosis and treatment. 9th ed. Philadelphia (PA): J.B. Lippincott Company; 1994. pp. 204-205.

30. Joshi P, Kaijkar M. A histochemical study of tissue eosinophilia in oral squamous cell carcinoma using Congo red staining. Dent Res J (Isfahan) 2013 Nov-Dec;10(6):784-789.

31. King GN, Healy CM, Glover MT, Kwan JT, Williams DM, Leigh IM, Worthington HV, Thornhill MH. Increased prevalence of dysplastic and malignant lip lesions in renaltransplant recipients. N Engl J Med 1995 Apr;332:1052-1057.
32. Peter CD, Shashidara R, Haragannavar VC, Samuel $P$, Sridhara SU. Assessment of tumor associated tissue eosinophilia (TATE) in oral squamous cell carcinoma using carbol chromotrope stain. Int J Odontostomat 2015;9(1):91-95.

33. Kargahi N, Razavi SM, Deyhimi P, Homayouni S. Comparative evaluation of eosinophils in normal mucosa, dysplastic mucosa and oral squamous cell carcinoma with hematoxylin-eosin, Congo red, and EMR1 immunohistochemical staining techniques. Electronic Physician 2015 Apr-Jun;7(2): 1019-1026.

34. Wong DTW, Elovic A, Matossian K, Nagura N, McBride J, Chou MY, Gordon JR, Rand TH, Galli SJ, Weller PF. Eosinophils from patients with blood eosinophilia express transforming growth factor B-1. Blood 1991 Nov;78(10):2702-2707.

35. Zini A, Czerninski R, Sgan-Cohen HD. Oral cancer over four decades: epidemiology, trends, histology, and survival by anatomic sites. J Oral Pathol Med 2010 Apr;39(4):299-305.

36. Looi L-M. Tumor-associated tissue eosinophilia in nasopharyngeal carcinoma. A pathologic study of 422 primary and 138 metastatic tumors. Cancer 1987 Feb;59(3):466-470.

37. Goldsmith MM, Cresson DH, Askin FB. Part II. The prognostic significance of stromal eosinophilia in head and neck cancer. Otolaryngol Head Neck Surg 1987 Apr;96(4):319-324.

38. Goldsmith MM, Belchis DA, Cresson DH, Merritt WD III, Askin FB. The importance of the eosinophil in head and neck cancer. Otolaryngol Head Neck Surg 1992 Jan;106(1): 27-33.

39. Pretlow TP, Keith EF, Cryar AK, Bartolucci AA, Pitts AM, Pretlow TG, Kimball PM, Boohaker EA. Eosinophil infiltration of human colonic carcinomas as a prognostic indicator. Cancer Res 1983 Jun;43(6):2997-3000. 